\title{
Study on Differentiated Management of Construction Land Based on China's Construction Land Discrepancy between Provinces
}

\author{
Ying-jie JIANG \\ School of Business Administration \\ Zhongnan University of Economics and Law \\ Wuhan, Hubei, China, 430073
}

\author{
Jun-feng ZHANG* \\ School of Public Administration \\ Zhongnan University of Economics and Law \\ Wuhan, Hubei, China, 430073 \\ Email: 13476284344@zuel.edu.cn.
}

\begin{abstract}
Research Objective: To optimize the spatial allocation of land resources, improve the utilization efficiency of construction land, and provide the technical basis for differentiated allocation of construction land. Method: The elasticity and contribution rate of land, capital and labor to economic growth is estimated through $C$-D production function model based on land allocation and the strategy for differentiated management is further proposed. Research Results: (1) The spatial difference of land construction in China is significant, in which the distribution quantity, the quality of use and the deviation degree of the structure for land supply roughly show the distribution of three steps; (2) The scale and output of construction land in Eastern China are higher than that in the central and western regions, and the structure is relatively reasonable. But the growth rate of construction land allocation and output in Eastern China is slower than that in the central and western regions; (3) The contribution rates of land, capital and labor to economic growth in China are $24 \%, 36 \%$ and $33 \%$ respectively, and the contribution rate of each province is from $12.86 \%$ to $36.96 \%$, which indicates that the construction land investment has effectively promoted economic growth, but the difference is significant at the provincial level; (4)According to the difference in the utilization and contribution rate of construction land, the allocation area in China can be divided into four types: key allocation area, moderate allocation area, connotation potential area and reduction allocation area. Research Conclusions: The inter-provincial allocation of construction land in China is not balanced, the supply and demand of construction land is not matched, and the structure of construction land is unreasonable. According to the inter-provincial difference in contribution rate, it is possible to construct a differential allocation strategy for construction land on the basis of zoning, including land allocation, quality control, structural adjustment, and fair guarantee. The strategy can change the traditional land allocation mode of "attaching much importance to efficiency, distribution and supply while little importance to fairness, management and structure."
\end{abstract}

Keywords-Spatial difference; Differential Configuration; Factor Contribution Rate; Construction Land

National Natural Science Foundation of China "Land Resource Endowment Spatial Heterogeneity, Resource Mismatch and Efficiency Improvement: Taking Wuhan City Circle as an Example (71603288)", Humanities and Social Sciences Research Project of Ministry of Education "Space Resource Spatial Heterogeneity and Function Mechanism and differential land policy research: Take Wuhan City Circle as an example (16YJC790133).

\section{INTRODUCTION}

The regional differences in land utilization and economic development in China are significant and highly correlated, but the characteristics of regional differences are not fully considered in the current land policy. There are still some outstanding issues such as contradictory supply and demand of construction land, unreasonable land utilization structure and the imbalanced development of land. In addition, the existing allocation model of construction land attaches much importance to efficiency, distribution and supply while little importance to fairness, management and structure. It is of great practical significance to explore the refined management and efficient allocation mode of construction land.

In recent years, many scholars have carried out a lot of researches on the total control volume, incremental allocation and management mode of construction land. In terms of total control, the existing literature has established a construction land scale measurement model based on the targets of ecological protection, economic efficiency, social development and multi-scenario, and then determined the total control volume of construction land. Angel predicted that the urban construction land area in developing countries in the world would increase from $300,000 \mathrm{~km}^{2}$ in 2000 to $770,000 \mathrm{~km}^{2}$ or even more ${ }^{[1]}$ in 2030 . The urban construction is expanding the most quickly in Asia and South America, in which it is necessary to control the scale of construction land. In terms of incremental allocation, the incremental allocation of construction land in view of the differences in ecological-economic advantages, food security-economic development, regional Gini coefficient and land use efficiency ${ }^{[3]}$ has become an outstanding issue that all scholars focus on. Ou Minghao, proposed partition allocation and management of construction land in Jiangsu Province based on the difference in construction land efficiency ${ }^{[4]}$. In terms of management mode, scholars have demonstrated and designed management models such as total volume control [5], partition control [6], differentiated management [7], and index market trading [8.' Zhang Zhanlu constructed a life cycle model of land utilization and management that ran through the entire process and proposed differentiated management measures for different stages [9]. In addition, many scholars believed that a corresponding management strategy should be proposed by integrating the allocation with the management of land 
construction to further improve the pertinence and effectiveness of the construction land management model. For example, Zhang Junfeng proposed to differentiate the management of construction land based on the contribution rate of land elements to economic growth ${ }^{[10]}$. The above researches provide a reference for exploring the allocation model of construction land, but most of them focus on the "quantity" such as construction land scale prediction and indicator allocation while ignoring the regional fairness and the "quality" management of construction land and taking countries or cities as research samples. Therefore, their research scale is restricted. The provinces in China are taken as research samples in this study to comprehensively consider the difference between the inter-provincial space of construction land and the contribution rate to economic development, and construction land control area is divided to establish differentiated allocation strategy of land construction and management model of innovative land construction with the balances in efficiency and fairness, quantity and quality as well as supply and demand.

\section{RESEARCH METHODS AND DATA}

\section{A. Research methods}

\section{1) Deviation index}

Structural optimization is the core goal of construction land management. How to measure the rationality of construction land structure has become a concern of many scholars. Based on the analysis of the construction land structure of typical cities in foreign countries and the actual situation in China, the reasonable proportion of infrastructure land, residential land, industrial land and commercial land in urban construction land is determined as $55: 20: 20: 5^{[12]}$. On this basis, the urban construction land structure deviation index $\mathrm{d}$ is constructed and its inter-provincial differences are analyzed. The smaller the deviation is, the more reasonable the land use structure will be. The calculation formula is as follows:

$$
D=\sqrt{\left(X-\frac{20}{45}\right)^{2}+\left(Y-\frac{5}{45}\right)^{2}+\left(Z-\frac{20}{45}\right)^{2}}
$$

Where $\mathrm{x}, \mathrm{y}$, and $\mathrm{z}$ represents the proportion of residential land, commercial land, and industrial land, respectively.

\section{2) The extended $C-D$ production function}

The C-D production function can be used to reflect the characteristics including factor marginal output, marginal replacement rate, and scale return change, and is widely used in estimating the contribution rate of production factor. The extended C-D production function is introduced, and the panel data model is used in this study to estimate the elastic coefficients $\alpha, \beta$, and $\gamma$ of urban construction land input (CL), capital input $(\mathrm{K})$, and labor input $(\mathrm{L})$ for urban economic growth. The specific formula is as follows:

$$
Q_{\mathrm{it}}=A K_{\mathrm{it}}^{\alpha} L_{\mathrm{it}}^{\beta} C L_{\mathrm{it}}^{\gamma}
$$

Take the logarithm on both sides:

$$
\operatorname{Ln} Q_{i t}=\ln A+\alpha \operatorname{lnK} K_{i t}+\beta \ln L_{i t}+\gamma \ln C L_{1 \mathrm{t}}
$$

3) Contribution rate measurement model
The relationship of each element contribution rate can be obtained as follows according to the Alfred Marshall elasticity concept and $\mathrm{CD}$ production function:

$$
\frac{\Delta A / A}{\Delta Y / Y}+\alpha \times \frac{\Delta K / K}{\Delta Y / Y}+\beta \times \frac{\Delta / L}{\Delta Y / Y}+\gamma \times \frac{\Delta C L / C L}{\Delta Y / Y}=1
$$

where $\mu_{\mathrm{K}}, \mu_{L}, \mu_{C L}$ are used to represent the contribution rate of capital, labor, and land elements to further obtain the following results:

$$
\begin{aligned}
& \mu_{K}=\alpha \times \frac{\Delta K / K}{\Delta Y / Y} \times 100 \% \\
& \mu_{L}=\beta \times \frac{\Delta L / L}{\Delta Y / Y} \times 100 \% \\
& \mu_{C L}=\gamma \times \frac{\Delta C L / C L}{\Delta Y / Y} \times 100 \%
\end{aligned}
$$

\section{B. Data source and processing}

In view of the availability of data, this study divides the country into 30 provinces, municipalities and autonomous regions (excluding Hong Kong, Macao, Taiwan, and Tibet) and into three regions: East, Central and West. ${ }^{1}$ The inter-provincial secondary and tertiary industry output value and index, fixed asset investment and index, urban construction land area, and secondary and tertiary industry labor force data are derived from the official website of the National Bureau of Statistics of China and the statistical yearbooks of the provinces from 2000 to 2015 . It should be noted that the area of urban construction land is the area of the built-up area (continuity, easy access, comparability, etc. , but it is smaller than the urban and rural construction land area, which may lead to a high contribution rate of construction land, but it has no significant impact on this study). In addition, the output value of the secondary and tertiary industries and the constant price of fixed assets are calculated by using the nominal GDP and the corresponding index ratio.

\section{ANALYSIS ON THE DIFFERENCES IN INTER-PROVINCIAL SPACE OF CONSTRUCTION LAND IN CHINA}

\section{A. Differences in the number of inter-provincial construction land}

In 2015, the total area of urban construction land in China was $51,600 \mathrm{~km}^{2}$ with an increase of $35,200 \mathrm{~km}^{2}$ in 2000 and an average annual growth rate of $21.14 \%$. In terms of absolute scale, from 2000 to 2015, the average annual construction land area of Shanghai, Shandong, Guangdong and other eastern coastal provinces exceeded $2200 \mathrm{~km}^{2}$, and that in other eastern provinces also exceeded $1200 \mathrm{~km}^{2}$. The annual average construction land in the western provinces is generally less than $800 \mathrm{~km}^{2}$, and that in the provinces such as Qinghai and Ningxia are less than $300 \mathrm{~km}^{2}$. The gap in the scale of inter-provincial allocation of construction land is very wide. Due to the large difference in the area of China's provinces, the ratio of

The eastern part includes 11 units in Beijing, Tianjin, Hebei, Liaoning, Shanghai, Jiangsu, Zhejiang, Fujian, Shandong, Guangdong, and Hainan; the central part includes 8 provinces of Shanxi, Jilin, Heilongjiang, Anhui, Jiangxi, Henan, Hubei, and Hunan; Inner Mongolia, Guangxi, Chongqing, Sichuan, Guizhou, Yunnan, Shaanxi, Gansu, Qinghai, Ningxia, Xinjiang 11 units. 
construction land to provincial area in the province is used to indicate the relative scale of construction land and to analyze the inter-provincial differences. As can be seen from Fig. 2, the relative scale of construction land in eastern China generally exceeds $0.8 \%$, among which that in Beijing, Shandong, Shanghai, Jiangsu, Zhejiang and Guangdong exceeds $2 \%$, while the relative scale of construction land in central and western provinces is generally less than $0.8 \%$ and that in the western provinces is generally less than $0.3 \%$, and the relative scale of construction land between provinces is significantly different. In summary, there are significant inter-provincial differences in the scale of construction land allocation in China: it gradually decreases from east to west and roughly presents three cascades. How to optimize the spatial layout of national land and promote regional coordinated development through the total and incremental allocation of construction land is a difficult problem to be solved in the construction land allocation model.

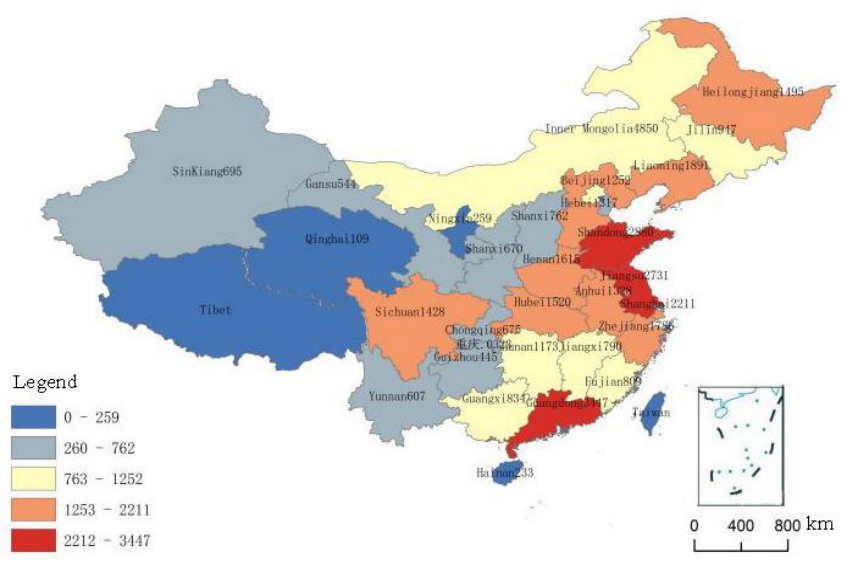

Fig. 1. The average absolute scale of China's inter-provincial construction land from 2000 to $2015\left(\mathrm{~km}^{2}\right)$
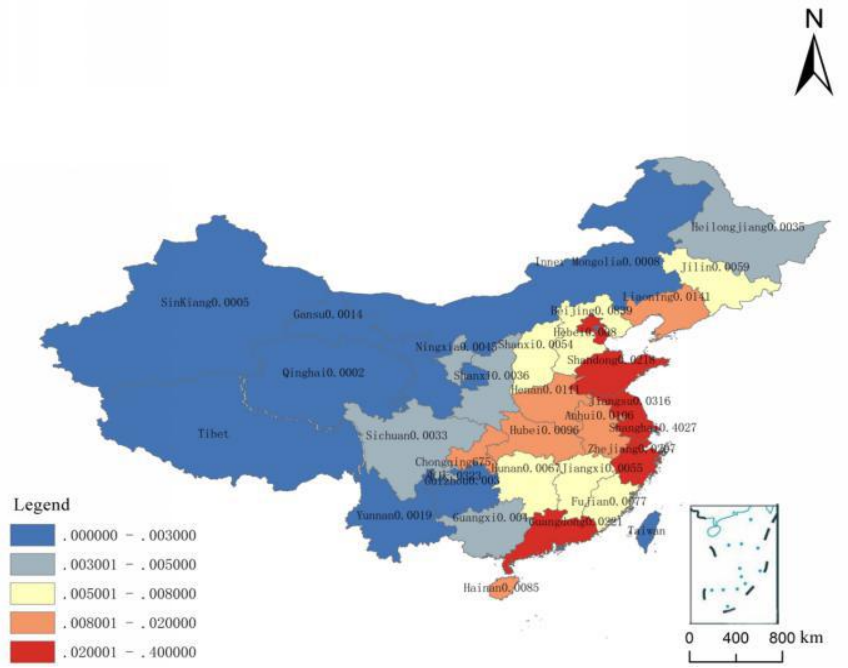

Fig. 2. The average relative scale of China's inter-provincial construction land from 2000 to 2015 (\%)

\section{B. Differences in the quality of interprovincial construction land}

The output intensity and output growth rate of construction land are used to reflect the quality of construction land and analyze its inter-provincial spatial characteristics. From the perspective of output intensity, the output intensity of China's construction land has decreased from east to west, and the average output value of the secondary and tertiary industries in the eastern, central and western regions is about 500 million Yuan $/ \mathrm{km}^{2}$ and 400 million Yuan $/ \mathrm{km}^{2}$ and 200 million Yuan / $\mathrm{km}^{2}$; respectively but the intensity of land use in different industries in the east is relatively balanced, the average output value of the secondary industry in the central province is significantly larger than that in the tertiary industry, and the intensity of land use between industries is uneven. From the perspective of output growth rate, the growth rate of China's construction land output gradually decreases from central, western and eastern regions, and the growth rate of construction land output in central regions is obviously bigger than that in eastern regions. The growth rate in western regions slightly slows down, and is slightly smaller than that in the eastern regions. This shows that with the implementation of the strategy of the rise of Central China and the adjustment of industrial structure, the allocation efficiency and output intensity of construction land in the central and western regions has been greatly increased. In summary, there are significant inter-provincial differences in the quality of China's construction land. The quantity distribution and the matching degree with industrial development should be fully considered in the allocation of construction land to improve the quality of construction land.

\section{Differences in the structure of interprovincial construction land}

From the perspective of China's supply structure of state-owned construction land in 2015, other land utilization for infrastructure accounted for $54.1 \%$, industrial and mining storage land accounted for $23.4 \%$, commercial land occupied $7.0 \%$, and residential land accounted for $15.5 \%$. In contrast, the ratio of China's industrial and commercial land utilization is relatively high, occupying and compressing residential land, and adjusting land utilization structure should be one of the ways to improve urban functions. According to the average scale of urban construction land in China from 2000 to 2015, the structural deviation index of China's construction land can be calculated, as shown in Fig. 3. It can be seen from Fig. 3 that the construction land deviation index in eastern China and some central provinces is small, indicating that the construction land structure is reasonable, which is mainly due to the implementation of the industrial structure adjustment and transfer strategy in eastern and central regions in recent years. The deviation index for western provinces is higher, mainly due to the higher proportion of residential and industrial land and the lower proportion of commercial land in these provinces. The deviation index is the lowest in Chongqing, which is inextricably linked with the "control housing policy" implemented by Chongqing. The unbalanced land utilization structure in other provinces and cities such as Fujian are due to the high proportion of industrial and commercial land and insufficient residential land, while that in Hainan is caused by 
the low proportion of residential and commercial land and the low industrial land. It can be seen that there are inter-provincial spatial differences in the degree of deviation of China's construction land structure and its causes. The rationality of the supply structure should be taken into account for the allocation of construction land.
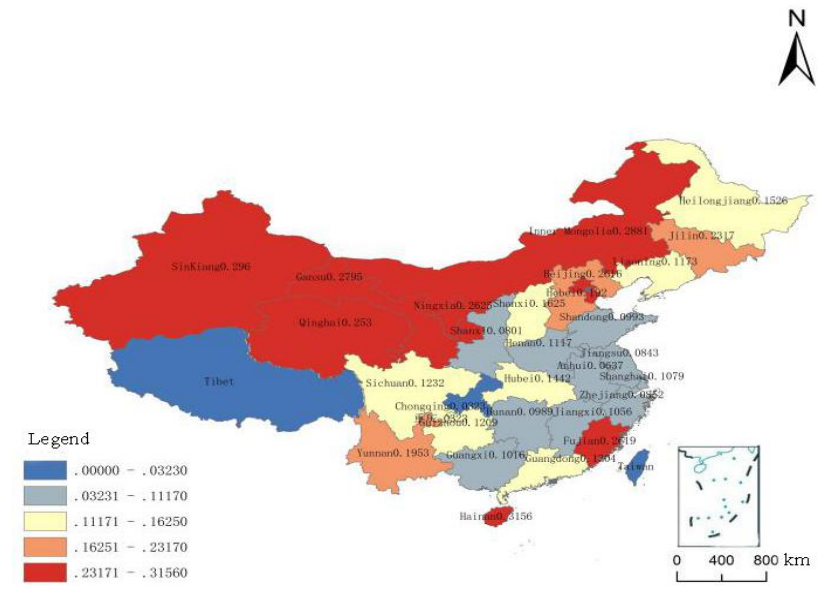

Fig. 3. China's inter-provincial construction land structure deviation index

\section{ANALYSIS ON THE DIFFERENCES IN THE INTER-PROVINCIAL CONTRIBUTION RATE OF CONSTRUCTION LAND IN CHINA}

\section{A. Model selection and estimation results}

This paper introduces the construction land investment, capital investment and the number of employees in the secondary and tertiary industries into $\mathrm{CD}$ production function model to explore the elasticity of factors and the role in economic growth. By using Stata to test the model form, it is found that the fixed effect model is more suitable. In order to eliminate heteroscedasticity and contribution, the production function of each province was estimated by zero regression method, and the goodness of fit of the model was above $90 \%$. The estimated results are shown in TABLE I.

TABLE I. PRODUCTION FUNCTION ESTIMATION AND CONTRIBUTION RATE CALCULATION RESULTS

\begin{tabular}{|c|c|c|c|c|c|c|c|c|c|c|}
\hline \multirow[b]{2}{*}{ Province } & \multicolumn{3}{|c|}{ Estimation coefficient } & \multicolumn{4}{|c|}{ Growth rate $(\%)$} & \multicolumn{3}{|c|}{ Contribution rate $(\%)$} \\
\hline & Capital & Labor & $\begin{array}{l}\text { Construction } \\
\text { land }\end{array}$ & $\begin{array}{c}\text { Economic } \\
\text { output }\end{array}$ & Capital & Labor & $\begin{array}{l}\text { Construction } \\
\text { land }\end{array}$ & Capital & Labor & $\begin{array}{c}\text { Construction } \\
\text { land }\end{array}$ \\
\hline Beijing & 0.413 & 0.294 & 0.132 & 10.24 & 1.51 & 7.45 & 7.55 & 37.75 & 28.27 & 12.68 \\
\hline Tianjin & 0.269 & 0.297 & 0.313 & 14. 49 & 1.85 & 6.24 & 5.57 & 24.02 & 27.84 & 28.59 \\
\hline Hebei & 0.276 & 0.313 & 0.251 & 11.30 & 1.93 & 3.50 & 6.49 & 25.64 & 28.83 & 23.92 \\
\hline Shanxi & 0.249 & 0.253 & 0.254 & 11.60 & 2.53 & 3.25 & 5.70 & 22.97 & 23.13 & 23.68 \\
\hline Inner Mongolia & 0.268 & 0.218 & 0.272 & 16.51 & 2.46 & 4.11 & 8.20 & 23.74 & 19.66 & 25.08 \\
\hline Liaoning & 0.343 & 0.287 & 0.296 & 11.58 & 2.11 & 2.70 & 4.54 & 31.11 & 26.69 & 28.11 \\
\hline Jilin & 0.342 & 0.281 & 0.243 & 12.68 & 1.86 & 4.82 & 7.30 & 30.73 & 26.05 & 22.85 \\
\hline Heilongjiang & 0.369 & 0.291 & 0.312 & 10.58 & 2.32 & 2.88 & 3.66 & 34.24 & 26.98 & 29.06 \\
\hline Shanghai & 0.382 & 0.411 & 0.159 & 10.31 & 1.74 & 5.95 & 11.76 & 35.05 & 39.38 & 16.21 \\
\hline Jiangsu & 0.352 & 0.231 & 0.282 & 12.74 & 2.53 & 4.35 & 11.03 & 31.83 & 21.29 & 27.58 \\
\hline Zhejiang & 0.348 & 0.341 & 0.242 & 11.60 & 2.07 & 4.55 & 9.09 & 32.01 & 31.85 & 23.46 \\
\hline Anhui & 0.332 & 0.329 & 0.318 & 13.11 & 2.31 & 5.40 & 6.20 & 29.85 & 30.75 & 30.04 \\
\hline Fujian & 0.292 & 0.351 & 0.298 & 12.85 & 1.64 & 6.21 & 9.83 & 26.12 & 32.94 & 29.20 \\
\hline Jiangxi & 0.391 & 0.252 & 0.287 & 13.09 & 2.48 & 4.71 & 8.96 & 35.34 & 23.15 & 27.94 \\
\hline Shandong & 0.409 & 0.268 & 0.243 & 12.62 & 2.34 & 5.52 & 9.97 & 37.26 & 25.30 & 23.44 \\
\hline Henan & 0.282 & 0.389 & 0.271 & 12.63 & 2.28 & 4.99 & 7.62 & 25.43 & 36.35 & 25.80 \\
\hline Hubei & 0.498 & 0.191 & 0.233 & 12.72 & 2.63 & 4.10 & 7.81 & 45.52 & 17.55 & 22.00 \\
\hline Hunan & 0.421 & 0.222 & 0.219 & 12.77 & 3.17 & 4.12 & 6.33 & 38.43 & 20.31 & 20.74 \\
\hline Guangdong & 0.381 & 0.324 & 0.236 & 11.97 & 1.98 & 4.90 & 8.58 & 34.61 & 29.98 & 23.27 \\
\hline Guangxi & 0.422 & 0.228 & 0.277 & 13.22 & 1.94 & 2.63 & 7.00 & 37.82 & 20.85 & 26.46 \\
\hline Hainan & 0.362 & 0.371 & 0.178 & 12.29 & 2.56 & 6.14 & 12.98 & 32.88 & 34.97 & 18.11 \\
\hline Chongqing & 0.358 & 0.232 & 0.281 & 14.18 & 2.34 & 3.67 & 10.14 & 32.27 & 20.88 & 27.01 \\
\hline Sichuan & 0.338 & 0.282 & 0.322 & 13.18 & 2.66 & 3.62 & 7.66 & 30.84 & 25.64 & 30.44 \\
\hline Guizhou & 0.348 & 0.091 & 0.312 & 13.21 & 2.18 & 1.09 & 9.10 & 31.59 & 8.04 & 29.87 \\
\hline Yunnan & 0.309 & 0.432 & 0.184 & 11.57 & 2.43 & 5.65 & 11.18 & 28.46 & 40.72 & 17.94 \\
\hline Shaanxi & 0.522 & 0.012 & 0.388 & 12.29 & 2.97 & 1.95 & 6.41 & 47.68 & 0.91 & 36.96 \\
\hline Gansu & 0.374 & 0.191 & 0.282 & 13.69 & 2.31 & 2.49 & 6.24 & 33.30 & 17.13 & 26.17 \\
\hline Qinghai & 0.296 & 0.228 & 0.212 & 11.57 & 2.74 & 6.16 & 7.20 & 27.62 & 21.89 & 20.18 \\
\hline Ningxia & 0.341 & 0.238 & 0.249 & 12.49 & 2.39 & 3.77 & 9.03 & 30.95 & 22.14 & 24.23 \\
\hline Xinjiang & 0.321 & 0.347 & 0.217 & 12.02 & 2.64 & 5.85 & 12.37 & 29.32 & 33.07 & 22.07 \\
\hline
\end{tabular}

\section{B. Factor elasticity and contribution rate analysis}

It can be seen from TABLE I that the estimation coefficients of land elements in all provinces in China are positive, indicating that the input of land elements promotes regional economic growth, but its growth elasticity is less than that of capital and labor. In terms of scale returns, $(\alpha+\beta+\gamma)<1$ in 30 provinces in China, which shows that the inputs of capital, labor and land elements suffer a 
diminishing change in scale returns. It is necessary to make innovative reforms on the supply factors, optimize the input structure of factors, and improve the efficiency of utilization. From the perspective of factor replacement rate, $(\alpha+\beta) / \lambda>1$ in 30 provinces in China. It shows that the substitutability of China's construction land elements is low. On one hand, China is still in the Malthus stage of economic development, economic growth is restricted by natural factors such as land, on the other hand, China's land resource allocation is mainly determined by government allocation and market mechanisms, and land cannot flow as freely as capital or property. In terms of factor elasticity, the land elements in central and western provinces are more flexible, because the urbanization process and economic development in these regions is increasing faster in recent years. The provinces with relatively small land element elasticity are mainly those areas with relatively high economic development level and relatively backward economic situation. This indicates that the allocation of land may be mismatched if based on the level of economic development and land output, and it is necessary to consider the matching between regional development orientation and land utilization demand as well as between land, capital, labor and other factors.

There are significant inter-provincial differences in the effects of China's land, labor, and capital on regional economic growth. In terms of land elements, the provinces with higher contribution rates include Shaanxi, Sichuan, Anhui, Heilongjiang, Guizhou and other places, all exceeding 29\%. This is determined by the rapid expansion of construction land and the benefits from higher land utilization in these regions in recent years; the cities with lower contribution rates include Beijing, Shanghai, Yunnan, Hainan and other places, all below $20 \%$ because the elasticity of land elements is low, and the substitution effect of capital and labor on land is obvious. It is also because of rough land utilization caused by unreasonable supply structure of production factors. Therefore, strengthening land supply side reform and differentiated management is a new impetus to promote economic growth. In terms of capital factors, provinces with higher contribution rates include Shaanxi, Hubei, Hunan, Guangxi, Beijing, Shandong, Jiangxi, and Shanghai, all of which account for more than 35\%. Capital investment in these provinces plays an important role in economic growth. The provinces need to optimize the investment structure and further enhance the role of capital in driving economic development; the provinces and cities with a lower contribution rate of capital factors include Shanxi, Inner Mongolia, Tianjin, Henan, Hebei and other provinces, all lower than 26\%. Capital investment in these regions mainly contributes to economic development. Although the contribution is not as much as expected, the growth rate of the capital factor is not the lowest, indicating that the capital input structure needs to be optimized to improve capital utilization efficiency. In terms of labor factors, Beijing, Shanghai, Henan, Hainan, Xinjiang, Fujian, and Zhejiang have higher contribution rates, all exceeding $30 \%$, indicating that labor factors play an important role in their regional economic development. It is necessary to improve the talent flow mechanism and optimize the labor structure. The contribution rate of labor force in Shaanxi, Guizhou, Gansu, Hubei, Inner Mongolia and other regions is relatively low, all below 20\%. Such regions should accelerate the adjustment of industrial structure, attract high-quality talents, and improve the output efficiency of the secondary and tertiary industries.

\section{CHINA'S CONSTRUCTION LAND DIFFERENTIAL ALLOCATION STRATEGY}

\section{A. Construction Land Differentiation Configuration Ideas and Basis}

From the above analysis, it can be seen that the inter-provincial differences in the quantity, quality and structure of construction land in China are significant, which conflicts with the current universal policy and may further lead to a series of problems such as uneven quantity allocation, imbalance between supply and demand, and unreasonable configuration structure. The differentiated configuration mode can adopt targeted configuration and management measures based on the difference in regional construction land, and effectively achieve the goal of "the balance between efficiency and fairness, between quantity and quality, as well as between supply and demand" for construction land allocation. The differentiated configuration is mainly based on regional characteristics and requirements of regional land utilization. This study firstly divides the differential allocation according to the difference of regional construction land, and then constructs a differentiated management mode of construction land from four aspects: land allocation, quality control, structural adjustment and fairness protection according to the characteristics of different zones.

\section{B. Construction land differential allocation strategy}

\section{1) Differential configuration partition}

According to the different configuration ideas of construction land, this study selects four indicators which are construction land contribution rate, relative quantity, output intensity and structural deviation index to divide the differential allocation of construction land and analyze its characteristics. The results are shown in TABLE II.

(1) Key configuration area. The key allocation area refers to the area where the construction land supply should be arranged in a key place during the allocation process of construction land. The construction land in the region plays a significant role in regional economic growth, the output intensity of construction land is large, and the land utilization structure is relatively reasonable. The proportion of construction land is $1.36 \%$, which is higher than in other regions, but there is still a large room for land development. In general, the demand for construction land in key allocation areas is large, the land utilization efficiency is high, and the land allocation is balanced. The construction land supply in the region should be guaranteed.

(2) Moderately configured area. The moderately allocated area refers to the area where the construction land supply is properly arranged during the allocation process of construction land. The construction land in the region plays a significant role in economic growth, the output intensity of construction land is large, and the land use structure is relatively reasonable. The proportion of construction land is $0.97 \%$ and the land development space is large. The demand and contribution of construction land in moderately allocated areas are relatively 
large, the efficiency and structure of land utilization are also relatively balanced and reasonable. The construction land should be properly allocated to ensure the basic demand for land utilization for economic development.

(3) Connotation potential area. The connotation potential area refers to the area where stock land should be used and the potentials for land utilization should be explored to meet the demand for construction land during the allocation process of construction land. The construction land in the region plays a significant role in economic growth. The land development space is affected by natural factors, but the output intensity of construction land in the region is not high, and the land use structure is seriously imbalanced. Therefore, to ensure the demand for capital construction land, the potential of land for stock use should be tapped through land redevelopment for stocks and potential expansion to ensure the land demand for economic development.

TABLE II. DIFFERENTIATED CONFIGURATION PARTITION TYPES AND MAIN INDICATORS

\begin{tabular}{|c|c|c|c|c|c|c|}
\hline Control area & Province & $\begin{array}{c}\begin{array}{c}\text { Average } \\
\text { contribution rate } \\
(\%)\end{array} \\
\end{array}$ & $\begin{array}{l}\text { Average land } \\
\text { use ratio }(\%)\end{array}$ & $\begin{array}{l}\text { Average output } \\
\text { intensity }(100 \\
\left.\text { million } / \mathrm{km}^{2}\right) \\
\end{array}$ & $\begin{array}{c}\text { Average land } \\
\text { structure } \\
\text { deviation } \\
\end{array}$ & $\begin{array}{l}\text { Mainland use } \\
\text { characteristics }\end{array}$ \\
\hline $\begin{array}{l}\text { Key allocation } \\
\text { area }\end{array}$ & $\begin{array}{c}\text { Tianjin, Liaoning, Jiangsu, Zhejiang, Anhui, } \\
\text { Fujian, Jiangxi, Henan, Guangxi, } \\
\text { Chongqing, Sichuan, Guizhou, Shaanxi }\end{array}$ & 28.57 & 1.36 & 13.91 & 0.12 & $\begin{array}{l}\text { Great contribution, high } \\
\text { output and reasonable } \\
\text { structure }\end{array}$ \\
\hline $\begin{array}{c}\text { Moderately } \\
\text { configured area }\end{array}$ & $\begin{array}{l}\text { Hebei, Shanxi, Inner Mongolia, } \\
\text { Heilongjiang, Hubei, Shandong, } \\
\text { Guangdong, Hunan }\end{array}$ & 23.90 & 0.97 & 12.97 & 0.16 & $\begin{array}{l}\text { Large contribution, high } \\
\text { output, and reasonable } \\
\text { structure }\end{array}$ \\
\hline Connotation pit & Jilin, Yunnan, Gansu, Qinghai, Ningxia & 22.27 & 0.26 & 9.71 & 0.24 & $\begin{array}{l}\text { Large contribution, low } \\
\text { output, structural } \\
\text { imbalance }\end{array}$ \\
\hline \begin{tabular}{c|} 
Decrement \\
configuration area
\end{tabular} & Shanghai, Hainan, Xinjiang, Beijing & 17. 27 & 0.12 & 9.52 & 0.25 & $\begin{array}{c}\text { Contribution, structural } \\
\text { imbalance }\end{array}$ \\
\hline
\end{tabular}

(4) Reduction allocation area. The reduction allocation area refers to the area where the construction land allocation should be reduced during the allocation process of construction land. In this area, there is a problem of unbalanced land use structure and low contribution of construction land to economic growth. It indicates that the economic development of the region is less dependent on construction land, and it is urgent to adjust and optimize the structural relationship between land and other production factors. Therefore, the way of reducing land allocation should be explored. Differentiation Configuration Strategy

According to the land use characteristics of differentiated configuration partitions and the coordination between efficiency and balance as well as between supply and demand, the differential configuration strategy of construction land is constructed from the aspects of construction land quantity allocation, quality control, structural adjustment and balanced development.

(1) Quantity-based differentiated configuration strategy. The key allocation area should appropriately release the total control constraints of construction land, give priority to meeting the demand for incremental land utilization and increase the scale and efficiency of land supply. Based on the scientific prediction on the scale and demand for construction land, the moderately allocated area will carry out total volume control and moderately meet the demand for incremental land utilization. The connotation potential area should control and rationally allocate incremental land, mainly relying on stock development, inefficient transformation, urban-rural land increase and decrease, to meet the construction land demand. The reduction allocation area strictly implements the total volume control and approval system for construction land, and explores the reduction allocation mode of construction land.

(2) Quality-based differentiated management strategy. The key allocation area should strengthen the post-approval supervision of construction land and the accountability of illegal and illegal land utilization, and improve the reward and punishment mechanism for land intensive utilization. The moderately allocated area should focus on establishing a dynamic monitoring mechanism and evaluation mechanism for land utilization to further improve the intensive utilization level of construction land. The connotation potential area needs to vigorously check idle land, remediate low-efficiency land, revitalize land for utilization, formulate land use standards, eliminate extensive land utilization and extension of construction land, strengthen the overall management and volume control of land utilization planning, and focus on improving the efficiency of construction land utilization. The reduction allocation area should increase the access threshold and use standards for construction land, and attach great importance to the overall improvement of construction land utilization efficiency.

(3) Differentiation adjustment strategy based on land utilization structure. The key allocation area should actively introduce high-tech industries, energy conservation and environmental protection industries and other industrial land projects and optimize the supply structure on the basis of ensuring the supply of infrastructure land by combining with the industrial adjustment policies of the region. The moderately allocated area needs to ensure the supply of infrastructure land and combine industrial adjustment policies, gradually phase out the "three high" industrial land types, reduce the proportion of industrial land supply, moderately increase the proportion of residential and commercial land supply, and optimize the supply structure of construction land. The connotation potential area should comprehensively consider the regional main function and development direction, and combine the structural adjustment of construction land with urbanization construction, industrial structure adjustment, improvement of people's livelihood and historical and cultural protection, and highlight the characteristics of regional land utilization. The reduction 
allocation area should adjust the industrial structure to promote the adjustment of land utilization structure, vigorously support and develop land projects for characteristic industries, and establish a mechanism that is highly compatible with the transformation of land utilization structure and regional industrial development.

(4) Land utilization development strategy. The first is to promote the development of new urbanization, accelerate the reform of land marketization, promote the flow of land, capital and labor factors in urban and rural areas, and conduct market transactions on surplus indicators under the constraints of total volume control and incremental distribution to further achieve a balance between supply and demand, while highlighting the value of land assets. The second is to establish a cross-regional land compensation mechanism and implement diversity compensation, mainly for industrial land (structure balance), construction land index (regional equilibrium), land acquisition (urban balance) and other aspects to improve the standards, methods and procedures of compensation and to clearly identify the subject, object and supervision mechanism of compensation. Finally, it is important to do a good job in planning and deal with the problems of convergence between different plans, guide land utilization by planning, and promote regionally balanced development.

\section{REFERENCES}

[1] ANGEL S, PARENT J, CIVCO D L, et al. The dimensions of global urban expansion: Estimates and projections for all countries, 2000-2050[J]. Progress in Planning, 2011, 75(2):53-107.
[2] GEYMEN A, BAZ I, Monitoring urban growth and detecting land cover changes on the Istanbul metropolitan area[J]. Environmental Monitoring and Assessment, 2008, 136(1-3):449-459.

[3] Wang Xirui, Xu Shi, Yang Xingdian, Wu Qun. Analysis of Temporal and Spatial Differences of Construction Land Use Efficiency and Total Factor Productivity in Jiangsu Province[J]. China Land Science, 2015, 29(05): 77-83. (In Chinese)

[4] Wu Bin, Guo Jie, Yin Shuang, Ou Minghao. Regional Differences in Land Use Efficiency and Zoning Control in Jiangsu Province [J]. China Land Science, 2013, 27(12): 25-31+45+97. (In Chinese)

[5] Li Xin, Ou Minghao. Supply land supply innovation: total control + differential regulation [J]. China Land, 2011, 08:47.

[6] Zhou Wei, Zhang Junfeng, Zhang Anlu, Xia Wei. Regional Differences and Differentiation Control of Contribution of Construction Land to Economic Growth-Taking Wuhan City Circle as an Example[J]. Agricultural Modernization Research, 2017, 38(01):74-80. (In Chinese)

[7] Ou Shengbin, Nong Fengshou, Chen Ligen. Differentiation Management of Construction Land: Theoretical Interpretation and Empirical Research-Taking Guangxi Beibu Gulf Economic Zone as an Example[J]. China Land Science, 2014, 28(01): 26-32. (In Chinese)

[8] Wang Ting. Research on the innovation of the linkage system for urban and rural construction land use [D]. Nanjing Agricultural University, 2012. (In Chinese)

[9] Lin Chao, Zhang Zhanlu. Construction of differentiated land management policy framework[J]. Journal of Northwest A\&F University (Social Science Edition), 2015, 15(03): 16-20. (In Chinese)

[10] Zhang Junfeng, Zhang Anlu. Differentiated Management of Construction Land Based on Factor Contribution Rate-Taking Wuhan City Circle as an Example[J]. Economic Geography, 2015, 35(10):171-178+193. (In Chinese)

[11] Huang Qifan. Establish five long-term mechanisms for real estate regulation [N]. First Financial Daily(Shanghai), 2017-05-31. (In Chinese) 